\title{
Carbon Dioxide Embolism - A Rare Complication in Laparoscopic Surgery
}

\author{
Oliveira S., Bernardo S., Ribeiro L., Amorim F., Fragoso P. \\ Department of Anaesthesiology - Hospital de Braga, Portugal
}

\begin{abstract}
Carbon dioxide $\left(\mathrm{CO}_{2}\right)$ embolism is a rare but potentially fatal complication during laparoscopic surgery. Due to the exponential growth of this type of surgery, the prompt identification and adequate treatment of $\mathrm{CO}_{2}$ embolism is crucial.
\end{abstract}

\section{CASE REPORT:}

- 우, 47 years-old

- ASA III: morbid obesity (BMI $44.2 \mathrm{~kg} / \mathrm{m}^{2)}$

- Scheduled for laparoscopic vertical gastrectomy

- ASA standard monitorization

- General anaesthesia

- Induction: propofol $2 \mathrm{mg} / \mathrm{kg}$, suxamethonium $1 \mathrm{mg} / \mathrm{Kg}$ and remifentanil $0.5 \mathrm{mcg} / \mathrm{kg} / \mathrm{min}$

- Maintainance: sevoflurane+ $\mathrm{O}_{2}+$ air.

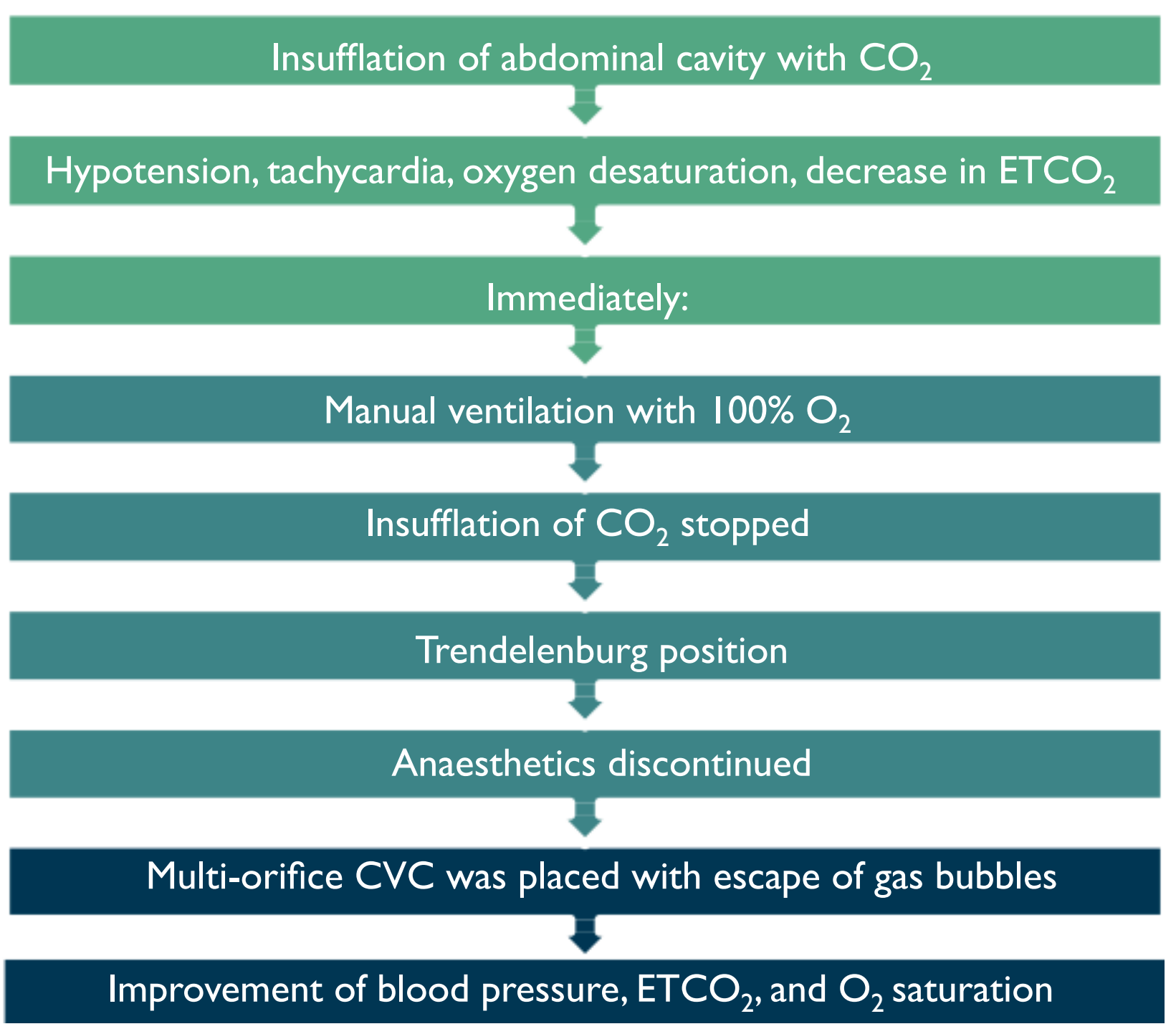

- Trans-thoracic echocardiogram confirmed the suspicion of $\mathrm{CO}_{2}$ embolism.

- Surgical team confirmed left hepatic lobe perforation.

- Cerebral, thoracic, abdominal and pelvic CT scans revealed otherwise irrelevant findings except hepatomegaly.

- Extubated and admitted to the High Dependency Care Unit for 24 hours, where she remained hemodynamically stable, with full recovery of pulmonary function and no neurological alterations.

- Discharged home 6 days after.
DISCUSSION: Severe cases of $\mathrm{CO}_{2}$ embolism described in literature occurred in laparoscopic surgery due to the erroneous placement of the Veress needle into a blood vessel or a parenchymal organ ${ }^{1}$. In this case, the presence of hepatomegally altered Palmer's point, increasing the risk of embolism.

Carbon dioxide embolism presents with ${ }^{1}$ :

Hypotension

Tachy- or bradiarrhythmias

\section{Asystole}

ECG with ST alterations

Sudden decrease in $\mathrm{ETCO}_{2}$

In this case, the diagnosis of $\mathrm{CO}_{2}$ embolism was based on the rapid decrease in $\mathrm{ETCO}_{2}$, hemodynamic instability, visualization of a perforated left hepatic lobe, and the escape of small gas bubbles through the CVC.

LEARNING POINTS: Gas embolism is a rare but potentially fatal complication during laparoscopic surgery ${ }^{1}$. A prompt, aggressive treatment is essential once the diagnosis of $\mathrm{CO}_{2}$ embolism is established. Anaesthesiologists and the surgical team should be aware of the signs, symptoms, risks and strategies to adopt when faced with a $\mathrm{CO}_{2}$ embolism.

\section{REFERENCES:}

1. Park EY et al. Carbon Dioxide Embolism during Laparoscopic Surgery. Yonsei Med J 2012: 53-3. 